\title{
Frequency of Methicillin-Resistant Staphylococcus aureus (MRSA) in Fattening Pigs in the State of Rio Grande do Sul, Brazil
}

\author{
Karine Ludwig Takeuti, Carolina Maciel Malgarin, Amanda Figueiredo Amaral \& \\ David Emilio Santos Neves de Barcellos
}

\begin{abstract}
Background: Staphylococcus (S.) aureus is an important nosocomial pathogen in humans and animals worldwide. The commonest class of antibiotics used to treat staphylococcal infections is the $\beta$-lactams. Frequently, $S$. aureus strains show high resistance to methicillin and other $\beta$-lactam antibiotics, called "Methicillin-resistant Staphylococcus aureus" (MRSA). Although MRSA has emerged at slower rate in domestic animals, it has frequently been found in the nasal cavity of healthy piglets and its transmission between pigs and swine handlers has already been studied. The aim of this work was to assess the presence of MRSA in finishing pigs in the state of Rio Grande do Sul, Brazil.

Materials, Methods \& Results: A total of 350 nasal swabs were collected from 10 to 20 week old finishing pigs. Sampling was performed in five pig farms in northeast Rio Grande do Sul State, Brazil. Swabs were stored in tubes without transport medium and carried to the laboratory under refrigeration. The specimens were cultured in selective and differential Agar (Baird Parker) and then were incubated at $37^{\circ} \mathrm{C}$ for $48 \mathrm{~h}$. After isolation of typical colonies of S. aureus, they were inoculated in BHI (Brain Heart Infusion) broth at $37^{\circ} \mathrm{C}$ for $24 \mathrm{~h}$ and tested for tube coagulase activity. Coagulase positive samples were selected for growth in Oxacillin Resistant Screening Agar (ORSA) supplemented with $2 \mathrm{mg} / \mathrm{L}$ of oxacillin. This media contains aniline blue to demonstrate mannitol fermentation. Oxacillin and $5.5 \% \mathrm{NaCl}$ have the capacity to reduce the growth of non-staphylococcal bacteria, selecting for MRSA. Blue colonies growth after 24 to $48 \mathrm{~h}$ of incubation at $37^{\circ} \mathrm{C}$ indicate the presence of positive MRSA strains. Specimens with at least one colony growing in ORSA within $48 \mathrm{~h}$ were considered resistant. Linear regression was performed in order to identify the association between herd size and MRSA frequency (SAS 9.4, 2012). Growth of S. aureus occurred on $18.0 \%$ of the samples and differences among farms were found. However, after incubation in ORSA only 18 (5.1\%) were MRSA positive, ranging from zero to $12.5 \%$ among farms. Significant correlation between herd size and MRSA frequency (adjusted $\mathrm{r}^{2}=0.978 ; P=0.001$ ) was observed. Discussion: In a previous study in pig herds in Brazil examining swine nasal swabs, $22.5 \%$ was positive for S. aureus and none for MRSA. One of 5 farms tested in our work also had no positive animals and 4 of them showed low frequencies, ranging from $1.7 \%$ to $12.5 \%$ with an average of $5.1 \%$. Our results were similar to those found in Asian countries, but were very different from European data. Some factors can be associated with MRSA frequency in pig farms, such as dust, air contamination, poor hygiene, age, herd size, replacement rate and number of sources. In the present work we found a strong positive correlation $\left(\mathrm{r}^{2}\right.$ adjusted $\left.=0.978 ; P=0.001\right)$ between herd size and MRSA frequency, such as detected by previous authors. It might occur due to a higher risk of bacterial introduction and higher pressure of infection, easing dissemination of MRSA. Herd size may be a crucial factor to explain the frequencies found, since farms had very similar facilities and handling practices. Although the average frequency has been low in this work when compared to other countries, MRSA was present in almost all farms. This bacteria is able to transmit mecA gene to $S$. aureus susceptible populations, increasing MRSA frequencies over time.
\end{abstract}

Keywords: swine, MRSA, resistance, nasal swabs.

DOI: $10.22456 / 1679-9216.80934$

Accepted: 6 May 2016

Published: 23 May 2016 


\section{INTRODUCTION}

Staphylococcus (S.) aureus is an important nosocomial pathogen in humans and in veterinary medicine worldwide [5,14]. The commonest class of antibiotics used to treat staphylococcal infections is the $\beta$-lactams. Recently, high resistance to methicillin and other $\beta$-lactam antibiotics in S. aureus strains started to grow, called "Methicillin-resistant Staphylococcus aureus" (MRSA) [19,21]. This resistance is related with the presence of penicillin-binding protein $2 \mathrm{a}$ (PBP2a), codified by the gene mecA. The protein interferes on $\beta$-lactam binding to bacterial cell, resulting on resistance to all $\beta$-lactams $[14,19]$. Although MRSA has emerged at slower rate in domestic animals when compared to humans, it has frequently been found in the nasal cavity of healthy pigs [20,21]. MRSA seldom causes clinical disease in pigs, but has already been identified in piglets with exudative epidermitis and no Staphylococcus hyicus isolation [18]. MRSA was also isolated from several organs from a variety of clinical cases, assuming that $S$. aureus could be the primary agent $[16,17]$. Moreover, transmission between pigs and swine handlers has been described $[3,10,20]$ and genetic similarity among strains was observed [10], resulting in public health concerns [21]. The aim of this study was to examine nasal swabs for MRSA presence in finishing pigs in the State of Rio Grande do Sul, Brazil.

\section{MATERIALS AND METHODS}

A total of 350 nasal swabs were collected from 10 to 20 week old finishing pigs. Sampling was performed in five pig farms in the northeast area from the state of Rio Grande do Sul, Brazil. Nasal swabs were stored in tubes without transport medium and carried to laboratory under refrigeration. They were then cultured in selective and differential Agar (Baird Parker $)^{1}$ and incubated at $37^{\circ} \mathrm{C}$ for $48 \mathrm{~h}$. After isolation of typical colonies of $S$. aureus, they were inoculated in BHI (Brain Heart Infusion) $)^{1}$ broth at $37^{\circ} \mathrm{C}$ for $24 \mathrm{~h}$ and tested for tube coagulase activity. Coagulase positive isolates were selected for inoculation in Oxacillin Resistant Screening Agar(ORSA) ${ }^{1}$ supplemented with $2 \mathrm{mg} / \mathrm{L}$ of oxacillin. This media contains aniline blue to demonstrate mannitol fermentation. The presence of oxacillin and $5.5 \% \mathrm{NaCl}$ grants the capacity to reduce the growth of non-staphylococcal bacteria, selecting for MRSA. The growth of blue colonies after 24 to $48 \mathrm{~h}$ of incubation at $37^{\circ} \mathrm{C}$ represents positive MRSA strains. Specimens with at least one colony in ORSA within 48 hours were considered resistant. Linear regression was performed to identify the association between herd size and MRSA frequency (SAS 9.4, 2012).

\section{RESULTS}

The frequencies and numbers of $S$. aureus and MRSA positive samples are presented in Table 1. From 350 samples, S. aureus was present in 63 (18.0\%) and a variable rate among the five farms was found. After incubation in ORSA, only 18 specimens $(5.1 \%)$ of MRSA were isolated in four out of five farms. In them, rates were low, ranging from 1.7 to $12.5 \%$. Significant correlation (adjusted $\mathrm{r}^{2}=0.978 ; P$ $=0.001$ ) between herd size and MRSA frequency was observed (Graphic 1).

\section{DISCUSSION}

Several methods can be used to detect MRSA, such as minimal inhibitory concentration (MIC), culture in solid agar supplemented with oxacillin or

Table 1. Frequency and number of positive samples for S. aureus and MRSA for each farm tested.

\begin{tabular}{ccccc}
\hline Farm & Herd size & Pigs tested & S. aureus positivity (\%) & MRSA positivity (\%) \\
\hline 1 & 508 & 60 & $1.7 \%(1)$ & $1.7 \%(1)$ \\
2 & 781 & 80 & $45.0 \%(36)$ & $12.5 \%(10)$ \\
3 & 654 & 80 & $28.7 \%(23)$ & $7.5 \%(6)$ \\
4 & 550 & 60 & $3.3 \%(2)$ & $1.7 \%(1)$ \\
5 & 480 & 70 & $1.4 \%(1)$ & $0 \%(0)$ \\
\hline \multicolumn{5}{l}{ Total } \\
\multicolumn{5}{l}{ Numbers between parentheses mean quantity of positive samples. }
\end{tabular}




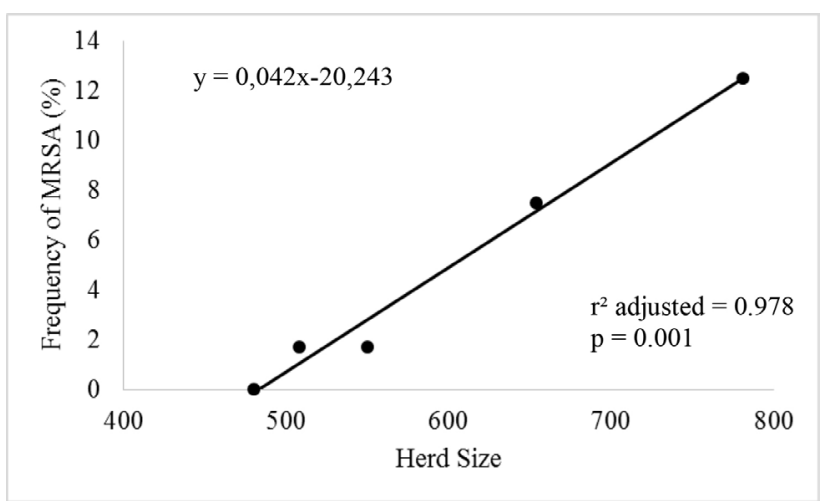

Graphic 1. Correlation between herd size and frequency of MRSA.

detection of PBP2a [19]. ORSA shows high accuracy for MRSA identification, since its sensibility can reach up to $98 \%$ [11] and specificity $95.5 \%$ to $98.3 \%$ [12]. Besides, molecular techniques are not always available in laboratories [19], which make the agar supplemented with oxacillin an efficient method for MRSA diagnostic.

Few papers about the frequency of MRSA in pigs in Brazil were published [2,15]. A previous study [15] found $22.5 \%$ positive $S$. aureus in swine nasal swabs from five farrow to finish farms and two slaughterhouses, similar to our results. However, no MRSA positive samples were found after analysis with ORSA or PCR. One of 5 farms tested in our work also showed no positive MRSA samples and $4(80 \%)$ showed low frequencies, ranging from $1.7 \%$ to $12.5 \%$ with an average of $5.1 \%$. Our results were similar to those found in Asian countries (0-7.8\% [13] to $11.8 \%$ [6]). On the other hand, Europe has a higher number of studies on MRSA infection in pig herds, which can reach frequencies of up to $81 \%$ [7].

Several factors can be associated with MRSA infection in pig farms, such as presence of high levels of dust, air contamination, poor hygiene, herd size, high replacement rate and multi-sourcing $[1,4,8,9]$. In the present work we found a strong positive correlation $\left(\mathrm{r}^{2}\right.$ adjusted $=0.978 ; P=0.001$ ) between herd size and MRSA frequency, as found by other authors $[1,4,8]$. This may occur due to a higher risk of bacterial introduction and higher infection pressure, easing dissemination of MRSA by direct contact between susceptible and infected animals. Herd sizes could have influenced the frequencies found, since farms had very similar facilities and handling practices. Production holdings tend to have higher MRSA frequencies than breeding holdings since there are differences of management, hygiene, health status and biosecurity between farms [8]. Considering our results from finishing herds, it could be speculated that MRSA rates in breeding holdings in Rio Grande do Sul State could be even smaller.

Although the average frequency was lower in our work when compared to other countries, MRSA was present in $80 \%$ of the herds. Furthermore, this bacteria is able to transmit mecA gene to $S$. aureus susceptible populations, increasing MRSA frequencies over time.

\section{CONCLUSION}

MRSA was detected in pig farms in the state of Rio Grande do Sul, Brazil, in four from five herds, reaching up to $12.5 \%$ of positive animals. Herd size was an important risk factor associated with MRSA presence, since larger pig populations showed higher MRSA frequencies.

\section{MANUFACTURER}

${ }^{1}$ Himedia®. Mumbai, Maharashtra, India.

Declaration of interest. The authors report no conflicts of interest. The authors alone are responsible for the content and writing of the paper.

\section{REFERENCES}

1 Alt K., Fetsch A., Schroeter A., Guerra B., Hammerl J., Hertwig S., Senkov N., Geinets A., Mueller-Graf C., Bräunig J., Käsbohrer A., Appel B., Hensel A. \& Tenhagen B.A. 2011. Factors associated with the occurrence of MRSA CC398 in herds of fattening pigs in Germany. BMC Veterinary Research. 7(69): 1-8.

2 Aquino G.V., Maluta R.P. \& Ávila F.A. 2012. Prevalence of methicillin-resistant Staphylococci on a farm: staff can harbour MRS when animals do not. Zoonoses and Public Health. 59: 1-3.

3 Armand-Lefevre L., Ruimy R. \& Andremont A. 2005. Clonal comparison of Staphylococcus aureus isolates from healthy pig farmers, human controls and pigs. Emerging Infectious Diseases. 11: 711-714.

4 Broens E.M., Graat E.A., Van Der Wolf P.J., Van De Giessen A.W. \& De Jong M.C. 2011. Prevalence and risk factor analysis of livestock associated MRSA-positive pig herds in The Netherlands. Preventive Veterinary Medicine. 102: 41-49.

5 Caddick J.M., Hilton A.C., Armstrong R.A., Lambert P.A., Worthington T. \& Elliott T.S. 2006. Description and 
critical appraisal of principal components analysis (PCA) methodology applied to pulse-field gel electrophoresis profiles of methicillin-resistant Staphylococcus aureus isolates. Journal of Microbiological Methods. 65: 87-95.

6 Cui S., Li J., Hu C., Jin S., Li F., Guo Y., Ran L. \& Man Y. 2009. Isolation and characterization of methicillin-resistant Staphylococcus aureus from swine and workers in China. Journal of Antimicrobial Chemotherapy. 64: 680-683.

7 De Neeling A.J., Van Den Broek M.J., Spalburg E.C., Van Santen-Verheuvel M.G., Dam-Deisz W.D., Boshuizen H.C., Van De Giessen A.W., Van Duijkeren E. \& Huijsdens X.W. 2007. High prevalence of methicillin resistant Staphylococcus aureus in pigs. Veterinary Microbiology. 122: 366-372.

8 European Food Safety Authority (EFSA). 2010. Analysis of the baseline survey on the prevalence of methicillinresistant Staphylococcus aureus (MRSA) in holdings with breeding pigs, in the EU, 2008 - Part B: factors associated with MRSA contamination of holdings; on request from the European Commission. EFSA Journal. 8(6): 1-67.

9 Gibbs S.G., Green C.F., Tarwater P.M. \& Scarpino P.V. 2004. Airborne antibiotic resistant and nonresistant bacteria and fungi recovered from two swine herd confined animal feeding operations. Journal of Occupational Environmental Hygiene. 1: 699-706.

10 Huijsdens X.W., Van Dijke B.J., Spalburg E., Van Stanten-Verheuvel M.G., Heck M.E., Pluister G.N., Wannet W.J. \& De Neeling A.J. 2006. Community-acquired MRSA and pig farming. Annals of Clinical Microbiology and Antimicrobials. 10: 5-26.

11 Karthy E.S. 2009. Performance of CHROM agar and oxacillin resistant screening agar base media for detection of methicillin resistant Staphylococcus aureus (MRSA) from chronic wound. Modern Applied Science. 3: 51-56.

12 Kluytmans J., Griethuysen A.V., Willemse P. \& Van Keulen P. 2002. Performance of CHROM agar selective medium and oxacillin resistance screening agar base for identifying Staphylococcus aureus and detecting methicillin resistance. Journal of Clinical Microbiology. 40: 2480-2482.

13 Lim S.K., Nam H.M., Jang G.C., Lee H.S., Jung S.C. \& Kwak H.S. 2012. The first detection of methicillin-resistant Staphylococcus aureus ST 398 in pigs in Korea. Veterinary Microbiology. 155: 88-92.

14 Markey B.K., Leonard F.C., Archambault M., Cullinane A. \& Maguire D. 2013. Clinical Veterinary Microbiology. In: Staphylococcus species. Toronto: Mosby Elsevier, pp.105-119.

15 Masson G.C.I.H., Ferreira G.S., Oliveira L.F. \& Carvalho S. 2012. Perfil de resistência a antimicrobianos de Staphylococcus aureus isolados de granjas e frigoríficos de suínos. Archives of Veterinary Science. 17: 1-14.

16 Meemken D., Blaha T., Tegeler R., Tenhagen B.A., Guerra B., Hammerl J.A., Hertwig S., Käsbohrer A., Appel B. \& Fetsch A. 2010. Livestock associated methicillin-resistant Staphylococcus aureus (LaMRSA) isolated from lesions of pigs at necropsy in northwest Germany between 2004 and 2007. Zoonoses and Public Health. 57: 413-148.

17 Van Der Wolf P.J., Rothkamp A., Junker K. \& De Neeling A.J. 2012. Staphylococcus aureus (MSSA) and MRSA (CC398) isolated from post-mortem samples from pigs. Veterinary Microbiology. 158(1-2): 136-141.

18 Van Duijkeren E., Jansen M.D., Flemming S.C., Neeling H., Wagenaar J.A., Schoormans A.H.W., Van Nes A. \& Fluit A.C. 2007. Methicillin resistant Staphylococcus aureus in pigs with exudative epidermitis. Emerging Infectious Diseases. 13(9): 1408-1410.

19 Velasco D., Tomas M.M., Cartelle M., Beceiro A., Perez A., Molina F., Moure R., Villanueva R. \& Bou G. 2005. Evaluation of different methods for detecting methicillin (oxacillin) resistance in Staphylococcus aureus. Journal of Antimicrobial Chemotherapy. 55: 379-382.

20 Voss A., Loeffen F. \& Bakker J. 2005. Methicillin-resistant Staphylococcus aureus in pig farming. Emerging Infectious Diseases. 11: 1965-1966.

21 Weese J.S. \& Van Duijkeren E. 2010. Methicillin-resistant Staphylococcus aureus and Staphylococcus pseudointermedius in veterinary medicine. Veterinary Microbiology. 140(3): 418-429. 